\title{
Çeşitli Klinik Örneklerden İzole Edilen Stafilokok Türlerinde Vankomisin Direncinin Araştırılması
}

\section{Investigation of vancomycin resistance in staphylococcus strains isolated from various clinical samples}

\author{
Satı Zeynep Tekin ${ }^{1}$, Sebahat Aksaray ${ }^{2}$, Fatma Bozkurt $^{3}$, Gülden Albayrak ${ }^{4}$, Jale Taşçığlu ${ }^{2}$ \\ ${ }^{1}$ Tıbbi Mikrobiyoloji Ana Bilim Dalı, Tıp Fakültesi, Çanakkale Onsekiz Mart Üniversitesi, Çanakkale, Türkiye \\ ${ }^{2}$ Klinik Mikrobiyoloji Laboratuvarı, Haydarpaşa Numune Eğitim ve Araştırma Hastanesi, İstanbul, Türkiye \\ ${ }^{3}$ Klinik Mikrobiyoloji Laboratuvarı, Kartal Dr. Lütfi Kırdar Eğitim ve Araştırma Hastanesi, İstanbul, Türkiye \\ ${ }^{4}$ Klinik Mikrobiyoloji Laboratuvarı, Çarşamba Devlet Hastanesi, Samsun, Türkiye
}

\section{ÖZET}

Giriş: Son yıllarda Staphylococcus aureus’ta sınırlı sayıda vankomisin direncinin yanında vankomisine azalmış duyarlılıktan da söz edilmektedir. Çalışmamızda çeşitli klinik örneklerden izole edilen Stafilokokus suşlarında vankomisin duyarlılık testi çalışılması amaçlanmıştır.

Yöntem: Metisiline dirençli olan toplam 164 Staphylococcus aureus ve koagülaz negatif stafilokok suşunda vankomisin agar tarama ve E-test yöntemiyle vankomisin duyarlılığı çalışılmış ve sonuçlar Clinical and Laboratory Standart Institute ve Europian Committee on Antimicrobial Susceptibility Testing kriterlerince irdelenmiştir.

Bulgular: Hasta örneklerinden izole edilen 164 (93 Metisilin Dirençli Staphylococcus aureus ve 71 Metisilin Dirençli Koagulaz Negatif Stafilokok) stafilokok suşunun E-Test ile değerlendirmesinde Clinical and Laboratory Standart Institute'ye göre vankomisine hassasiyeti azalmış ya da dirençli suşa rastlanmadı. Europian Committee on Antimicrobial Susceptibility Testing'e göre Brain Heart infüzyon agarda üreyen 6 Metisilin Dirençli Staphylococcus aureus suşunun 3'ü, 7 Metisilin Dirençli Koagulaz Negatif Stafilokok suşunun 1'i Vankomisin'e dirençli tespit edilmiş̧ir.

Sonuç: Minimum İnhibitör Konsantrasyon değerindeki küçük değişiklikler bile klinik olarak anlamlı olabileceğinden, Vankomisin Minimum İnhibitör Konsantrasyon değeri doğru tespit edilmelidir.

Anahtar kelimeler: Stafilokok, vankomisin, antibiyotik direnci.

\begin{abstract}
Introduction: Besides the few investigation demonstrating the vancomycin resistance towards Staphylococcus aureus in recent years, it has been also reported a decreased sensitivity of these bacteria to vancomycin. In the present study, it was aimed to evaluate sensitivity test in staphylococcus strains isolated from various clinical samples.

Methods: A total of 164 staphylococcus strains consisting of Methicillin Resistant Staphylococcus aureus ( $\mathrm{n}=93$ ), and Methicillin Resistant Coagulase Negative Staphylococcus $(\mathrm{n}=71)$ were included in this study. The vancomycin agar screening and E-test methods were used to assess vancomycin sensitivity, and results were interpreted to Clinical and Laboratory Standard Institute and European Committee on Antimicrobial Susceptibility Testing criteria.

Results: After assessing the strains by using E-Test, neither decreased sensitivity, nor resistance to vancomycin was determined according to Clinical and Laboratory Standard Institute. However, 3 of 6 Methicillin Resistant Staphylococcus aureus, and 1 of 7 Methicillin Resistant Coagulase Negative Staphylococcus reproduced in Brain Heart Infusion Agar were found to be resistant to vancomycin according to European Committee on Antimicrobial Susceptibility Testing.

Conclusion: Because even small changes can be clinically significant, Minimum İnhibition Concentration value of vancomycin should be correctly determined.
\end{abstract}

Keywords: Staphylococcus, vancomycin, antibiotic resistance.

Başvuru / Submission: Nisan / April 21, 2016

Kabul / Acceptance: Nisan / April 22, 2016

Yazışma / Correspondence: Dr. Satı Zeynep Tekin, Tıbbi Mikrobiyoloji Ana Bilim Dalı, Tıp Fakültesi, Çanakkale Onsekiz Mart Üniversitesi, Çanakkale, Türkiye

E-mail: satitekin@yahoo.com

Atıf / Cite: Tekin SZ, Aksaray S, Bozkurt F, Albayrak G, Taşçıŏlu J. Çeşitli klinik örneklerden izole edilen stafilokok türlerinde vankomisin direncinin araştırılması. Fam Pract Palliat Care. 2016;1(2):43-47 


\section{GíRiș}

Staphylococcus aureus (S.aureus)'un en iyi bilinen özelliklerinden birisi klinik kullanıma yeni giren antibiyotiklere bile kısa sürede farklı mekanizmalarla direnç geliştirebilmesidir. 1980'lerin sonlarına doğru vankomisin dirençli enterokok (VDE)'lar artan oranlarda görülmeye başlamıştır. Vankomisinle ilgili direnç genlerinin enterokoklardan stafilokoklara geçtiği bilinmekte ve in vivo koşullarda bu genlerin klinik izolatlara da aktarılabileceği öngörülmektedir. Günümüzde rehber olarak kullanılmaya başlanan Europian Committee on Antimicrobial Susceptibility Testing (EUCAST)'e göre S.aureus'un vankomisin klinik Minimum İnhibitör Konsantrasyon (MİK) sınır değeri $>2$ $\mathrm{mg} / \mathrm{L}$ olduğunda direnç varlığından söz edilir. Önceleri "intermediate" (orta) olarak tanımlanan grup kaldırılarak, vankomisin sınır değerleri düşürülmüştür. Glikopeptid direnci Van A genine bağlı yüksek düzey ve Van A'dan bağımsız kodlanan düşük düzey direnç gibi farklı mekanizmalarla görülebilmektedir. $\mathrm{Bu}$ yüzden Van A dişı kodlanan düşük düzey vankomisin direncini saptayabilmek için glikopeptid "intermediate" S. aureus (GISA) ve heterodirençli glikopeptid "intermediate" S. aureus (hGISA) tanımları korunmuştur. Tedaviye yanıt alınamayan durumlarda hGISA araştırılmalı, etkenin S. aureus olduğu durumlarda vankomisin MIK değerinin belirlenmesi gerekmektedir. (1-4)

Son y1llarda görülen başka bir problem ise vankomisin MIK değerlerinde görülen yükselmedir. MIKK değerlerinin Clinical and Laboratory Standart Institute (CLSI) 'a göre dirençli olarak değerlendirilmemesine rağmen bazı çalışmalarda MİK değerlerinde yükselmenin, tedaviye yanıtsızlıkla birlikte ortaya çıktığı görülmüştür. Bu durum "MIC creeping" olarak adlandırılmaktadır.(5-6). Tüm bu durumlar göz önüne alındığında ülkemizde henüz vankomisine direnç bildirilmemesine ve vankomisin MIK duyarlılığına rağmen tedavide başarısızlık gibi durumların görülmesi, hGISA gibi suşların varlığı nedeniyle çalışmamızın yapıldığı dönemdeki sonuçlar, günümüze uygun olarak CLSI ve EUCAST'in her ikisine göre yorumlanmıştır.

\section{YÖNTEM}

Çalışmamızda aralık 2009-nisan 2011 tarihleri arasında Haydarpaşa Numune Hastanesi klinik ve poliklinik hastalarına ait örneklerden izole edilen 93 Metisilin dirençli S.aureus (MRSA) ve 71 Metisilin dirençli koagülaz negatif stafilokok (MRKNS) suşu incelemeye alınmıştır. Klinik örneklerin kültür plaklarına ekimi ve $35^{\circ} \mathrm{C}^{\prime}$ de inkübasyon sonrasında 1 $2 \mathrm{~mm}$ çaplı, düzgün yüzeyli, mat beyaz-sarı, hemolizlihemolizsiz kolonilerden Gram boyama yapılmıştır. Gram boyama sonucunda Gram pozitif küme yapan kok şeklindeki bakteriler incelemeye alınmıştır. Katalaz, koagülaz ve DNase pozitif suşlar S.aureus olarak tanımlanmıştır. Katalaz pozitif, koagulaz ve DNase negatif suşlar koagülaz negatif stafilokok olarak değerlendirilmiştir. S.aureus ve koagülaz negatif stafilokok suşlarında metisiline direncini saptamak için disk difüzyon yöntemi uygulanmıştır. 0,5 McFarland bulanıklığına göre ayarlanmış olan koloni süspansiyonu Mueller-Hinton agar plaklarına yayıldıktan sonra $30 \mu \mathrm{g}$ sefoksitin içeren disk agar yüzeyine yerleştirilmiştir. $35^{\circ} \quad C^{\prime}$ de 24 saatlik inkübasyondan sonra, sefoksitin diski için inhibisyon zon çapının S.aureus için $\leq 22 \mathrm{~mm}$, koagülaz negatif stafilokoklar için $\leq 25 \mathrm{~mm}$ olduğu saptanan suşlar, metisiline dirençli kabul edilmişir. CLSI M100-S19, M02-A10, M07-A8 ve EUCAST kılavuzundan yararlanılmıştır (11). Vankomisin direncini taramak amacıyla; içinde $6 \mu \mathrm{g} / \mathrm{ml}$ vankomisin olacak şekilde Brain-Heart İnfüzyon (BHI) agar hazırlanmıştır. MRSA ve MRKNS suşlarının tümü için 0,5 McFarland bulanıklığında koloni süspansiyonu hazırlandıktan sonra $10-15 \mathrm{~mm}$ çapında bir alana ekimleri yapılmıştır. Ekimler $35^{\circ} \mathrm{C}$ 'de 24 saatlik inkübasyondan sonra değerlendirilmiştir. Agar yüzeyinde birden fazla koloni üremesi, vankomisine olası azalmış duyarlılık göstergesi olarak kabul edilmiştir. Tüm suşların Etest yöntemiyle CLSI ve EUCAST kılavuzlarına göre MİK değerleri araştırılmıştır. $\mathrm{Bu}$ testlerin kontrolünde S.aureus ATCC 29213 (MIK 0,5-2 $\mu \mathrm{g} / \mathrm{ml}$ ) ve Enterococcus faecalis ATCC 51299 (vankomisin dirençli) standart suşları kullanılmıştır.

\section{BULGULAR}

Haydarpaşa Numune Eğitim ve Araştırma Hastanesi Klinik Mikrobiyoloji Laboratuvarı'nda, hasta örneklerinden izole edilen 164 (93 MRSA ve 71 MRKNS) stafilokok suşundan MRSA suşları en sık yara örneklerinden (\%40); MRKNS suşları ise en sık kan kültürlerinden (\%83) izole edilmiştir. Klinik örneklere göre dağılım Tablo 1'de gösterilmektedir.

Tablo 1. Stafilokok suşlarının klinik örneklere göre dağılımı (n)

\begin{tabular}{lrr}
\hline $\begin{array}{l}\text { Materyal } \\
\text { Cinsi }\end{array}$ & MRSA & MRKNS \\
\hline Kan kültürü & 15 & 59 \\
Kateter & 0 & 1 \\
Trakeal aspirat & 20 & 2 \\
BOS & 3 & 5 \\
Yara & 37 & 3 \\
sürüntüsü & & 1 \\
İdrar & 4 & 0 \\
Balgam & 2 & 0 \\
$\begin{array}{l}\text { Burun } \\
\text { sürüntüsü }\end{array}$ & 12 & 71 \\
TOPLAM & 93 & \\
\hline
\end{tabular}

Çalışmaya alınan 164 suşun 13’ü vankomisin tarama agarda üremiştir $(\% 7,9)$. Vankomisin tarama agarda üremeyen 151 suşun E-test ile MİK değerleri ikinin altında bulunmuştur.

E-test ile 93 MRSA suşunun $87(\% 93,5)$ 'sinde MIKK değeri $<2 \mu \mathrm{g} / \mathrm{ml}, 71$ MRKNS suşunun 64 (\%90,1)'ünde MİK değeri $<4 \mu \mathrm{g} / \mathrm{ml}$ bulunmuştur. CLSI'ya göre çalışmamızda vankomisine hassasiyeti azalmış ya da dirençli suşa rastlanmamışken EUCAST'e göre Brain Heart infüzyon agarda üreyen 6 MRSA suşunun 3'ü, 7 MRKNS suşunun 1'i Vankomisin'e dirençli tespit edilmiştir. (Tablo 2 ve 3 ). 
Tablo 2. Ölçek puanlarının karşılaştırılması, ortalama \pm standart sapma (ss)

\begin{tabular}{|c|c|c|c|c|c|}
\hline \multirow{2}{*}{$\begin{array}{l}\text { Suşlar } \\
\text { (n) }\end{array}$} & \multicolumn{5}{|c|}{ E-test MİK Değerleri, $\mu g / m l(\%)$} \\
\hline & $<2$ & 2 & 3 & 4 & 6 \\
\hline $\begin{array}{l}\text { MRSA } \\
(93)\end{array}$ & $\begin{array}{c}87 \\
(\% 93,5)\end{array}$ & $\begin{array}{c}3 \\
(\% 3,2)\end{array}$ & $\begin{array}{c}3 \\
(\% 3,2)\end{array}$ & 0 & 0 \\
\hline $\begin{array}{l}\text { MRKNS } \\
\text { (71) }\end{array}$ & $\begin{array}{c}64 \\
(\% 90,1)\end{array}$ & $\begin{array}{c}1 \\
(\% 1,4)\end{array}$ & $\begin{array}{c}3 \\
(\% 4,2)\end{array}$ & $\begin{array}{c}2 \\
(\% 2,8)\end{array}$ & $\begin{array}{c}1 \\
(\% 1,4)\end{array}$ \\
\hline
\end{tabular}

\section{TARTIŞMA}

Stafilokoklar hem toplumdan kazanılmış, hem de hastane kaynaklı enfeksiyon etkenleri arasında ilk siralarda yer almaktadır. National Nosocomial Infection Surveillance verilerine göre 2000 yılının Aralık ayında yoğun bakım ünitelerinde MRKNS'ların \%75'inde, S.aureus'ların \%47'sinde vankomisin kullanıldığı rapor edilmiştir (7). MRSA ülkemizde de hastane enfeksiyonu etkenleri içinde ilk siralarda yer almakta ve yıllar içinde görülme sıklığında artış saptanmaktadır (8). Ancak son yıllarda Enfeksiyon Kontrol Komitelerinin yoğun çalışmaları ile hastane kaynaklı enfeksiyonlar içinde MRSA oranının azaldığı görülmektedir. $(9-10 * * * *)$.

Tablo 3. Vankomisin Tarama agarda üreyen suşların MíK değerleri ile CLSI ve EUCAST’e göre karşılaştırılması

\begin{tabular}{|c|c|c|c|c|}
\hline Suş no & $\begin{array}{c}6 \mu \mathrm{g} / \mathrm{ml} \text { vankomisin } \\
\text { içeren } \mathrm{BHI} \text { agarda üreme }\end{array}$ & $\begin{array}{r}\text { E-test ile } \\
\operatorname{MiK}(\mu \mathrm{g} / \mathrm{ml})\end{array}$ & CLSI & EUCAST \\
\hline 1-MRSA & + & 3 & $S$ & $\mathrm{R}$ \\
\hline 2-MRSA & + & 2 & S & S \\
\hline 3-MRSA & + & 3 & $S$ & $\mathrm{R}$ \\
\hline 4-MRSA & + & 2 & $S$ & $S$ \\
\hline 5-MRSA & + & 2 & $S$ & $S$ \\
\hline 6-MRSA & + & 3 & $S$ & $\mathrm{R}$ \\
\hline 7-MRKNS & + & 2 & $S$ & $S$ \\
\hline 8-MRKNS & + & 3 & $S$ & $S$ \\
\hline 9-MRKNS & + & 3 & $S$ & S \\
\hline 10-MRKNS & + & 3 & $S$ & $S$ \\
\hline 11-MRKNS & + & 4 & $S$ & $S$ \\
\hline 12-MRKNS & + & 4 & $S$ & $S$ \\
\hline 13-MRKNS & + & 6 & $S$ & $\mathrm{R}$ \\
\hline
\end{tabular}


Başta yoğun bakım üniteleri olmak üzere hastanelerin bazı bölümleri, MRSA ve MRKNS enfeksiyonları açısından daha yüksek risk oluşturmaktadır. Altmışbeş yaşın üstünde, açık cilt yaraları olan, hastanede uzun süre yatan, operasyon geçiren ya da çok sayıda invaziv girişim uygulanan, böbrek yetmezliği olan ve geniş spektrumlu/uzun süre antibiyotik tedavisine maruz kalan hastalar hem endojen floranın hem de ortam bakterilerinin tehditi altındadır. Bu koşullar dirençli bakteri suşlarının seçilmesine yol açarken, MRSA enfeksiyon ve kolonizasyonunu da kolaylaştırmaktadır. Hastane kaynaklı koagülaz negatif stafilokokların \%50'si metisiline dirençlidir (11).

Glikopeptid antibiyotikler MRSA enfeksiyonlarının tedavisinde özel bir konuma sahipken son yıllarda tedavide klinik başarının azaldığını gösteren çalışmalar vardır. Malloval ve arkadaşları (12) Belçika'da hastanede yatan hastaların çeşitli klinik örneklerinden izole ettikleri 455 MRSA suşunda E-test yöntemiyle vankomisin MIKK değerlerini araştırmışlar, çalışma sonucunda GISA suşlarına rastlamadıklarını ancak populasyon analiziyle 3 tane $(\% 0,7) \mathrm{h}$ GISA suşu bulduklarını bildirmişlerdir.

h-GISA suşlarının prevalansı Avrupa ülkelerinden İtalya, Almanya, Fransa ve Hollanda'dan sirasiyla \%1,1, \%0,21, $\% 0,6, \% 6$, Tayland ve Kore' den ise \%1,93 ve \%0,54 olarak bildirilmiştir (13-15).

Zohreh ve arkadaşlarının 2014 yılında E-test yontemi ve CLSI kriterlerine göre vankomisin MİK değerlerinde artış ve mortaliteyle ilişkisine yönelik yaptıkları çalışmada anlamlı bir fark bulunmamasına rağmen duyarlı bile olsa artan MİK değerleri açısından glikopeptid kullanımında dikkatli olunması gerektiğine vurgu yapmışlardır.(16)

Ülkemizde yapılan çalışmalarda vankomisine direnç henüz bildirilmemiştir.. Yurdumuzda ilk kez Gülay ve arkadaşlarının (17) klinik örneklerden elde ettikleri 95 MRSA kökeninde vankomisin direncini araştırdıkları çalışmada, mikrodilüsyon yöntemiyle kökenlerin beşinde $(\% 5,3)$ vankomisine azalmış duyarlılı (MİK $8 \mu \mathrm{g} / \mathrm{ml}$ ) bildirilmiştir.

Sancak ve arkadaşları (18) tarafından yapılan çalışmada, 256 MRSA suşunda GISA saptanmamış ancak yapılan populasyon analizinde 46 suş h-GISA olarak değerlendirilmiştir.

Derbentli ve arkadaşlarının (19) yaptığı bir başka çalışmada, stafilokoklarda vankomisin direnci saptanmamış, fakat MRSA suşlarının \%0,3'ünde vankomisine, \%0,8'inde teikoplanine azalmış duyarlılık saptanmıştır. MRKNS suşlarında bu oranlar sırası ile $\% 0,4$ ve $\% 1,3$ olarak bildirilmiştir.

Dinç ve arkadaşlarının (20) 2011 yılında E-test yöntemiyle yaptıkları çalışmada MİK değeri $3 \mu \mathrm{g} / \mathrm{ml}$ olarak saptanan bir MRSA suşun (\%1), mikrodilüsyon yöntemi ile de MIKK değeri $3 \mu \mathrm{g} / \mathrm{ml}$ olarak bulunmuş ve CLSI standartlarına göre vankomisine orta derecede duyarlı (GISA), EUCAST kriterlerine göre vankomisin dirençli (VRSA) olarak değerlendirilmiş olup Makro Etest yöntemi ile de aynı MİK değeri $(3 \mu \mathrm{g} / \mathrm{ml})$ bulunan suşun heterojen GISA olmadığı kabul edilmiştir.

Tekin ve arkadaşları (21) 2014 yılında Metisiline dirençli stafilokokları E test yöntemiyle ve CLSI kriterlerine göre değerlendirdikleri çalışmalarında vankomisine dirençli suş bulmadıklarını bildirmişlerdir.
Ülkemizde Atmaca ve arkadaşlarının (22) yaptığı bir çalışmada Vankomisinin duyarlı sınırlarda bulunmasına rağmen artan MIK değerlerinin mortalite ile yakın ilişkili olabileceği konusuna dikkat çekilmişlerdir.

Dünya çapında h-GISA, GISA, GRSA bildirimlerinin artması nedeniyle ülkemizde de bu dirençler yönünden dikkatli olunmalı, tanıda antibiyotikler için daha standart olan yöntemlerle toleransın araştırılmasına önem verilmelidir.

Sonuç olarak; MİK değerindeki küçük değişiklikler bile klinik olarak anlamlı olabileceğinden, vankomisin MiK değeri duyarlılık sınırını geçtiğinde, olası tedavi başarısızlığını önlemek için Vankomisin MİC değeri doğru tespit edilmelidir.

Not: Bu çalışma Tıpta Uzmanlık Tezinden yayın haline
getirilmiştir.

Çıkar çatışması: Bildirilmedi.

Finansal destek: Bildirilmedi.

\section{KAYNAKLAR}

1. Ulusoy S, Usluer G, Ünal S. Gram Pozitif Bakteri Enfeksiyonlar1: Ankara 2004. 9-38

2. Hawkes M, Barton M, Conly J, Nicolle L, Barry C, FordJones EL. Community-associated MRSA: superbug at our doorstep CMAJ. Jan 2007;(176-1):54-6.

3. Başustaoğlu A. Antibiyotiklere direnç mekanizmaları ve Çözüm Önerileri: Glikopeptitlere Direnç. Hastane İnfeksiyonları Dergisi 2001;(5) 202-9

4. EUCAST Klinik ve/veya epidemiyolojik önemi olan direnç mekanizmaları ve direnç özelliklerini saptama kılavuzu. Temmuz 2013. Online erişim 21,04,2016. https://www.klimud.org/content/126/eucast

5. Hawser SP, Bouchillon SK, Hoban DJ, Dowzicky M, Babinchak T. Rising incidence of Staphylococcus aureus with reduced susceptibility to vancomycin and susceptibility to antibiotics: a global analysis 2004-2009. Int J Antimicrob Agents 2011; 37(3): 219-24.

6. Hanaki H, Hososaka Y, Yanagisawa C, et al. Occurrence of vancomycin-intermediate-resistant Staphylococcus aureus in Japan. J Infect Chemother 2007; 13(2): 118-21.

7. National Nosocomial Infections Surveillance (NNIS) System Report, Data Summary from January 1992-April 2000, Issued June 2000. Am J Infect Control 2000;28(6):429-48.

8. Arslan H, Tunçbilek S, Nazlıer S: Nosokomial infeksiyon etkeni olarak izole edilen stafilokoklarda glikopeptid antibiyotiklerin etkinliği, 8. Türk Mikrobiyoloji ve İnfeksiyon Hastalıkları Kongresi, Program ve Özet Kitabı Antalya 1997:784.

9. Woodford N, Livermore D. Infections caused by grampositive bacteria: a review of the global challenge 2009;59(S1) S4-S16.

10. Taşova Y. Dirençli Gram Pozitif Bakteri İnfeksiyonlarında Güncel Tedavi. Yoğun Bakım Dergisi 2012; 10(3):147-64

11. Boyce SM, William\&Wilkins: Coagulase-negative Staphylococci, 'Mayhall CG (ed): Hospital Epidemiology and Infection Control' Baltimore 1996:360

12. Malloval FO, Carricajo A, Delavenna F et al. Detection of an Outbreak of Methicillin-Resistant Staphylococcus 
aureus with Reduced Susceptibility to Glycopeptides in a French Hospital. Clin Microbiol Infect 2004; 10:459-61.

13. Griethysen AV, Veen AV, Buiting A, Walsh T, Kluytmans J. High percentage of methicillin-resistant Staphylococcus aureus isolates with reduced susceptibility to glycopeptides in the Netherlands. J Clin Microbiol. 2003(41):2487-91.

14. Trakulsomboon S, Danchaivijitr S, Rongrungruang $Y$. First report of Methicillin-resistant Staphylococcus aureus with reduced susceptibility to vancomycin in Thailand. $\mathbf{J}$ Clin Microbiol. 2001(39):591-5.

15. Kim MN, Hwang SH, Pyo YJ, Mun HM, Pai CH. Clonal Spread of Staphylococcus Heterogenously Resistant to Vancomycin in a University Hospital in Korea. Journal of Clinical Microbiology, Apr. 2002: 1376-80.

16. Aminzadeh Z., Yadegarynia D., Fatemi A.,Tahmasebian D. E., Armak S.A. Vancomycin Minimum Inhibitory Concentration for Methicillin-Resistant Staphylococcus aureus Infections; Is There Difference in Mortality Between Patients? Jundishapur J Microbiol. 2014 October; 7(10): e12831.

17. Gülay Z, Biçmen M, Atay T, Öktem İMA, Yuluğ N: Staphylococcus aureus suşlarının Fusidik asit ve Glikopeptid antibiyotiklere duyarlılığının incelenmesi, Dokuz Eylül Üniv Tıp Fak Derg 2000;14(3):227-31.

18. Sancak B, Ercis S, Menemenlioğlu D, Çolakoğlu S, Hasçelik G: Methicillin-resistant Staphylococcus aureus heterogeneously resistant to vancomycin in a Turkish University Hospital, J Antimicrob Chemother 2005;56(3):519-23.

19. Derbentli Ş. Stafilokoklarda Antibiyotik Direnci 20032004 Türkiye Haritası. Ankem Dergisi 2005;19(Ek-2):5467.

20. Dinç F, Dinç F.T.,Akca B., Sınırtaş A.M., Özakın C. Kandan İzole Edilen Metisiline Dirençli Staphylococcus aureus (MRSA) Suşlarının CLSI ve EUCAST Kriterlerine Göre Vankomisin, Tigesiklin, Linezolid ve Daptomisin İn Vitro Duyarlılık Sonuçları. Türk Mikrobiyol Cem Derg 41(3):120-126, 2011

21. Tekin A. Dal T., Deveci Ö.,at all. Invitro susceptibility to methicillin, vancomycin and linezolid of staphhylococci isolatted from bloodstream infections in eastern Turkey. Braz. J. Microbiol.July/Spt. 2014 45(3) 829-33

22. Atmaca Ö., Zarakoğlu Köşker P., Karahan C., Çakır B., Ünal S. Risk Factors and Antibiotic Use in MethicillinResistant Staphylococcus aureus Bacteremia in Hospitalized Patients at Hacettepe University Adult and Oncology Hospitals (2004-2011) and Antimicrobial Susceptibilities of the Isolates: A Nested Case-Control Study. 